\title{
Political Attitudes Vary with Detection of Androstenone
}

\author{
Amanda Friesen \\ IUPUI \\ Mike Gruszczynski* \\ Indiana University-Bloomington \\ Kevin B. Smith \\ University of Nebraska-Lincoln
}

John R. Alford

Rice University

*All correspondence should be directed to Mike Gruszczynski, The Media School at Indiana University-Bloomington, mgruszc@iu.edu. An earlier version of this paper was presented at the annual meeting of the Midwest Political Science Association, Chicago, Illinois, April 2011. Financial support provided by the National Science Foundation (BCS-0826828).

Abstract: Building on a growing body of research that suggests political attitudes are part of broader individual and biological orientations, we test whether the detection of the hormone androstenone is predictive of political attitudes. The particular social chemical analyzed in this study is androstenone, a non-androgenic steroid found in the sweat and saliva of many mammals, including humans. A primary reason for scholarly interest in odor detection is that it varies so dramatically from person to person. Using participants' self-reported perception of androstenone intensity, together with a battery of survey items testing social and political preferences and orientations, this research supports the idea that perceptions of androstenone intensity relate to political orientations, most notably preferences for social order, lending further support to theories positing the influence of underlying biological traits on sociopolitical attitudes and behaviors.

Key words: Androstenone; olfaction; political orientations; social order 
Understanding the origins of public opinion has expanded from elite messaging, socialization, and group membership to include the possibility that attitudes toward group life may have some basis in our biology. That is, the social signals humans have generated and interpreted throughout the history of our species may continue to influence complex social behaviors like politics. Below we explore whether the detection of the hormone androstenone is predictive of political attitudes. We selected androstenone because of the variation in detection and preference for this odor in adult populations. If sensitivity to disgust ${ }^{12} 3$, interpretation of facial expressions ${ }^{4}$, and responses to startling noises ${ }^{5}$ are associated with social protective policies, then it stands to reason that the ancient and powerful sensory detection system of olfaction also may continue to provide social cues today.

Olfaction is the most chemically-direct component of the sensory system, with its signals registering in the emotional centers of the brain without elaborate filters or mechanisms. ${ }^{6}$ Biologically, olfaction's origins are based on little more than a protein serving as a receptor -- a simple and direct sensory system that allowed primitive organisms to move toward or away from given chemicals detected in the environment. Neurophysiologist John Allman argues the evolutionary foundation of all behavior builds off this simple avoid-approach system, which in its most basic form can be thought of as a "lust-disgust" signal that attracts (or repels) organisms to particular environmental stimuli ${ }^{7}$. In more complex organisms, this primitive and powerful regulation mechanism evolved to allow olfaction to detect and transmit information about the social as well as the physical environment.

This is reflected in its unusually direct link to the CNS, as regions of the human brain tasked with olfaction and socioemotional processes overlap ${ }^{8}$. Odors register directly in the olfactory bulb, which is proximate to brain areas at the heart of emotion, memory, and sociality, 
including the amygdala, hypothalamus, and orbitofrontal cortex ${ }^{9}$. As a result, odors exert a strong influence on behavior. For example, subjects presented with a strawberry while smelling the odor of an orange, for example, spread their grips as if they were reaching for the larger fruit. Conversely, participants spread their grip too narrowly in grasping an orange if the prevailing odor is of strawberries ${ }^{10}$. Retail outlets manipulate ambient smells because research suggests consumer behavior is situationally affected by odors ${ }^{11}{ }^{12}$, even when the scent is not strong enough to register in conscious thought ${ }^{13}$.

Individual-level variation in the physiological constitution of nervous systems is known to correlate with differences in behavior ${ }^{14}$, which has been suggested to be due at least in part to individual differences in the number of olfactory receptor genes ${ }^{15}$. Due in part to physiological variations in the way stimuli are sensed, some organisms experience the world differently than others and, as Vigil notes, how individuals process social stimuli differently may partly explain differences in political orientations ${ }^{16}$. For example, individuals who see emotionally neutral faces as threatening ${ }^{17}$ or who startle when they hear a loud and unexpected noise ${ }^{18}$ show an increased likelihood of harboring certain politically conservative orientations. Given that a large proportion of sensory input does not pass through consciousness ${ }^{19}$, it is important to note that the effects of sensory variations do not require the individual to be aware that something has been sensed for the sensory variations to manifest in behavior. We suggest that olfaction is a helpful next step in efforts to understand how and when political attitudes and orientations are biologically substantiated.

\section{The Odor of Politics?}

Given the central role olfaction plays in disgust detection and disgust's link to politics ${ }^{20} 21$ ${ }^{22}{ }^{23}$, we have borrowed its theoretical organizational scheme to think about how olfaction may 
also connect to political opinions. Recent research identifies three primary functions of disgust: pathogen avoidance, mate choice, and social interaction -- sometimes labeled microbes, mating, and morality 242526 . As mentioned, the precursor to olfaction originated as a mechanism for identifying substances that single-celled organisms should approach or avoid. When more complex organisms began acquiring nutrients through ingestion rather than absorption, olfaction became a crucial indicator of what to ingest and, more importantly, what not to ingest. Thus, the first of three primary uses of the olfactory system is pathogen avoidance.

The second is mating. When certain animals began reproducing sexually rather than asexually, olfaction became an integral part of the process and continued to play that role even in humans 27282930 , heightening the attractiveness of some prospective sexual partners while greatly reducing the attractiveness of others. Recent research in political science also supports the notion that olfaction may mediate the connection between political agreement and mate choice ${ }^{31}$.

The third fundamental role of olfaction pertains to morality or the following of social norms -- the focus of this research. From the beginning of social life, olfaction has been employed to identify offspring, close kin, and out-group members. Within a group, it is also valuable in identifying dominance hierarchies, conspecifics to avoid and befriend, and one's own place within the group 323334 . In short, the chemosignals crucial to olfaction serve as a means of social communication, especially as it relates to reproductive, territoriality, and both intergroup and intra-group behavior ${ }^{36}$. When new challenges arise, existing systems typically modify so when social life began, the uses of olfaction broadened to include identifying offspring and to provide other socially valuable information. With the growing complexity of social life, individuals expanded the use of olfaction from its role in small scale dominance hierarchies and later, we test, to mass scale social life; that is, to politics. 
Support for this conception is found in the physiology of olfaction. In mammals, olfaction depends on approximately 1,000 different receptors, each designed to detect the presence of a specific ambient, odor-causing chemical ${ }^{37}$. Any given receptor is capable of identifying only a single chemical, though many odors contain more than one chemical and so activate a portfolio of olfactory receptors. The variety of receptor combinations allows organisms to identify a multitude of distinct odors, estimated to be 10,000 for homo sapiens ${ }^{38}$. As might be expected, many olfactory receptors correspond to the chemicals emitted by foodstuffs; however, numerous other receptors are targeted toward odors associated with reproduction and sociality. For example, the peptides oxytocin and vasopressin, long known to have marked social implications $s^{39} 40$, are detected by receptors in the olfactory system, and blocking these receptors in rats has been demonstrated to impair social recognition abilities and associated behaviors ${ }^{42}$. This fits with D'Amasio's ${ }^{43}$ somatic marker hypothesis that emotion and its physiological correlates are key to decision making.

Even so, olfaction traditionally has not been taken seriously as a correlate of political orientations and behavior ${ }^{44}{ }^{45}$, perhaps because of the erroneous assumption that political judgments arise solely from conscious sensory input—a notion that recent research is beginning to correct ${ }^{46}{ }^{47}$. To date, the impetus for analyzing olfaction largely comes from the aforementioned broader interest in the connection of disgust to political views. Haidt and colleagues find judgments of political conservatives to be influenced more by "purity" concerns than those of liberals ${ }^{48}$, and work by Inbar, Pizarro, and Bloom ${ }^{49}$ shows a correlation between self-reported disgust sensitivity and political stances, particularly those pertaining to sexual attitudes such as gay marriage. The connection between political stances and disgust makes sense when one considers research demonstrating the impact of disgust on social interactions, 
particularly with regard to violations of deep-seated norms such as marriages or emotional partnerships ${ }^{50}$. Moreover, Smith et al. ${ }^{51}$ find that physiological responses to disgusting images, independently from self-reports, correlate with political attitudes toward gay marriage, though these effects seem to be moderated by gender ${ }^{52}$. As certain odors strongly evoke disgust, it is not surprising to find olfactory parallels to the correlation between disgust and certain social judgments.

Though previous research is suggestive that the primitive "pathogen avoidant" role of olfaction trickles over into moral and political judgments, our interest is in whether the aspect of olfaction that evolved specifically for social and political life is related to political orientations. In some respects, this is the more obvious approach, but it may be less obvious because sociallyrelevant odors tend to be much less likely than purity or disgust odors to enter conscious awareness. Many pathogen-relevant disgusting smells are immediately and unavoidably detectable, and responses to them visible (a contorted expression, gagging or vomiting), but at most realistic levels, the odors of socially relevant chemicals do not enter conscious awareness. This subtle nature of reactions to odors may have discouraged scholars from correlating political orientations and social odors. In any event, despite variations in how attitudes toward authority predict political differences ${ }^{53} 54$ and how olfaction relates to mate choice by political attitudes ${ }^{55}$, we can locate no previous research that has tested for link between olfaction and attitudes toward authority and security.

\section{Androstenone}

The particular social chemical analyzed in this study is androstenone, a non-androgenic steroid found in the sweat and saliva of many mammals, including humans ${ }^{56}$. Androstenone is a generic term typically applied to any of 16 chemical substances in the same family ${ }^{57}$. Its 
centrality to humans is indicated by ERP studies showing that androstenone elicits faster cortical responses than a broad range of "control" odorants ${ }^{58}$. Androstenone, androstadienone, and androstanol are all part of this family of hormones, and which compound or substance researchers select for experiments seems more related to availability or popularity "than a logical and rational process of falsification." 59

Scholarly interest in odor detection is due to its dramatic variation from person to person $^{60} 61$. Menashe et al. ${ }^{62}$ call olfaction receptors "one of the most pronounced cases of functional population diversity in the human genome." With regard to androstenone, though all humans produce it - with adult men producing higher levels than adult women -- numerous studies consistently report wide variation in both the intensity and valence with which androstenone is detected within the population. Even at concentrated dosages, some people do not smell androstenone at all. They are often referred to as androstenone anosmics and constitute somewhere between 10 and 40 percent of the population ${ }^{63}{ }^{64}$. Others report the odor of androstenone to be overwhelming while still others are somewhere in the middle, thereby making the distribution reasonably continuous. Among osmics, there are pronounced differences in whether androstenone is detected favorably or unfavorably. Some find the odor pleasing and compare it to sandalwood, incense, or vanilla; others dislike the odor and believe it to be similar to ammonia, sweat, or urine $\mathrm{s}^{6566}$.

One reason for the marked variation in androstenone detection appears to be genetic differences. Heritability studies suggest a strong genetic role ${ }^{68}{ }^{69}$, and a gene labeled OR7D4 may be related to detection of androstenone (and the closely related androstadienone) but not to any other known odors ${ }^{70}$ and has paved the way to examine the direct connections between specific genes and associated behaviors ${ }^{71}$. Though androstenone detection is undoubtedly 
affected by environmental factors ${ }^{72}$, including the frequency of exposure to the substance perhaps in the same way that taste sensitivity moderates visceral disgust sensitivity ${ }^{73}$ - it is also partially based in genetics and "differences in the OR7D4 gene may have behavioral consequences beyond the psychophysical tests in a smell laboratory"74.

Androstenone is also clearly important to human social life, and seems especially relevant to social perception and cognition ${ }^{75}$. A number of studies confirm that the odor of androstenone alters social judgments, especially how females judge males. For example, after being exposed to androstenol (the alcohol version of androstenone), females usually evaluate males more favorably while males tend to be unaffected. ${ }^{76}$ One study even finds that females are more likely to sit in a chair that has been treated with androstenone than one that has not ${ }^{77} 78$.

Yet, few studies address androstenone's potential relevance to the broader (non-mating) aspects of social life. Filsinger et al. ${ }^{79}$ find that exposure to androstenone led men to rate other men as more passive. Kline, Schwartz, and Dikman ${ }^{80}$ report that individuals more sensitive to the odor of androstenone tend to be less likely to give evidence of the personality trait known as defensiveness, in which negative traits (such as anger) are assigned to others but not assigned to oneself. Hummer and McClintock ${ }^{81}$ document that androstadienone (closely related to androstenone) heightens sensitivity and attention to emotions. For example, participants receiving androstadienone (instead of a control substance) on their lip exhibit reduced response times in a dot probe task if the dots appeared on the same side as an emotional (rather than a neutral) face. So, on one hand, androstenone detection is linked to a type of socio-pathology (defensiveness), but on the other, to the ability to use emotional cues to make decisions (akin to D'Masio's somatic marker theory). As interesting as these studies may be, given the complete absence of any previous research on the effects of androstenone detection on politically rather 
than sexually relevant variables ${ }^{82}$, at this stage, a priori theoretical expectations must be viewed as provisional. Despite androstenone's acknowledged "relevance to social life," we simply have little empirical or theoretical work on which to build.

Given androstenone's role in providing information about mating strategy and possibly social hierarchy related to mate selection, it might be possible that heightened olfactory sensitivity to androstenone could be positively related to authoritarianism or conservatism, or at least to that subset of conservative positions most pertinent to an established and secure social order. Vigil ${ }^{83}$ finds that conservatives are more likely than liberals to attribute certain emotions (such as anger) to faces presented on a computer screen, and Oxley et al. ${ }^{84}$ find that individuals who are conservative on selected "social order" issues are more likely than liberals to display an elevated startle reflex subsequent to an unexpected loud noise. Sensitivity to the emotional content of other people's odors, as well as to the emotional content of their faces, may be conducive to certain right-of-center political orientations.

A related line of reasoning is that, given its close relationship with testosterone ${ }^{85}$, a substance often associated with aggression, competition, and risk-taking ${ }^{86}{ }^{87}$, those who readily detect androstenone in those around them may be more likely to seek comfort and protection in the arms of the secure, traditional social order that conservatives often hold out as the end goal of their policy preferences. Thus, heightened sensitivity to odors such as androstenone may be consistent with favorable attitudes toward decisive leaders, protection from both in-group rulebreakers and out-group invasions, and a desire to promote traditional rather than avant-garde lifestyles. This is not to say that conservatives possess higher levels of androstenone or testosterone than liberals but that they may be better able to detect hormones related to aggression. In sum, previous research provides a basis for exploring a positive relationship 
between the intensity with which people report detecting a standardized concentration of androstenone and political beliefs designed to promote a stable, secure social order with a clear authority structure 88899091.

\section{Methods}

The data used in this analysis were collected as part of a larger study conducted in the summer of 2010. A professional survey organization sent informational letters (to promote response rate) to a random sample of adults in the area surrounding a medium-sized Midwestern city, then followed up by phone, recruiting a sample of 340 individuals to come to a lab on a nearby college campus in exchange for $\$ 50$. Though the sample was drawn randomly, we make no claims that those eventually participating constitute a random sample. The restriction to a small part of the country and the requirement that participants travel to the lab undoubtedly introduce biases, but a national random sample is not necessary to explore the possible connection between political orientations and variations in androstenone detection. Still, we are pleased to note that the group eventually participating is not a student sample and matches nicely with demographic figures on the overall adult population in the United States, though these individuals are more educated and predominantly white. The mean participant was 45 years old, had some college education and earned $\$ 60,000$ annually. The sample was 55\% female and 95\% white. Also reflecting the population from which it was drawn, marginally more participants self-identified as conservatives than as liberals, with many others identifying as moderates, but the important consideration is that substantial variation in political orientations was present.

Participants first completed a computer-based survey on their political beliefs, personal tastes and preferences, personality traits, and demographic characteristics. After completing a separate experimental task in an adjacent lab, they were escorted to a well-ventilated room where 
they began a second computer-based survey protocol. Participants first answered the set of olfactory screening items used by Keller et al. ${ }^{92}$ that catalogue any characteristics or experiences that may interfere with the ability to detect odors overall (general osmia); for example, seasonal allergies, current respiratory infection, chronic alcoholism, endoscopic surgery, and current use of hormonal birth control. These questions were used as a strict filter. Any individual who indicated that one or more of these conditions applied to them was excluded from subsequent analyses, resulting in an eventual sample of 136. Thus, these filters for factors known to degrade the ability to measure general osmia at the time of the study substantially reduce the number of available cases, with seasonal allergies being the main culprit. Individuals removed from the analysis may be able to detect androstenone when their impediments to normal olfactory function (like seasonal allergies) are absent but need to be removed from the analysis because their current condition prevents accurate assessment of their detection abilities ${ }^{93}$. The characteristics of the individuals in the reduced sample are quite similar to those for the complete sample: $51.4 \%$ male, some college, annual income of just under $\$ 60,000,91.2 \%$ white, and mostly conservative (39.4\%) and moderate (34.3\%). Similarly, differences between the full and reduced sample on our variables of interest (Table 1) were modest. For most of these variables, mean differences were not statistically significant and were substantively trivial.

After completing the screening questions, all participants - including those we later excluded due to possible osmic interference - engaged in an olfactory test. Amber-colored $40 \mathrm{ml}$ bottles, labeled only with a number, were set up on the table next to the computer in the room. Directions on the computer screen instructed the participants to pick up each bottle, beginning with one labeled "\#1", unscrew the cap, place the bottle under their nose, and inhale gently. After recapping the bottle, they were asked to rate the strength or intensity of the odor (with 1 being 
"smelled no odor" and 10 being "smelled a strong odor") and then the favorability or valence of the odor (with 1 being "unpleasant odor" and 10 being "pleasant odor"). This same process was then repeated for the remaining bottles.

The bottles were presented in the same order for all participants. Bottle \#1 contained $5 \mathrm{ml}$ of a solution of androstenone ( $5 \alpha$-androst-16-en-3-one) with solvent propylene glycol at a dilution of 1:1000. Though androstenone has 16 distinct derivatives, scholarly studies of androstenone typically employ one of two: $\Delta 4,16$-androstadien-3-one (also known as androstadienone) or $5 \alpha$-androst-16-en-3-one. They are closely related, and we employ the latter here in order to keep our work consistent with that of Keller et al. ${ }^{94}$ and Knaapila et al. ${ }^{95}$.

Bottle \#2 contained only propylene glycol $(5 \mathrm{ml})$ as a check to ensure that the solvent itself did not have a detectable odor ${ }^{96}$. Bottle \#3 contained our control odor: $5 \mathrm{ml}$ of a solution of citronella oil (Chinese 85/35\%) diluted at 1:10,000 in paraffin oil. Citronella was used because it is an odor that is easy to detect and has no known specific anosmia ${ }^{97}$. The central variable of interest in this analysis is the intensity with which each respondent reported detecting androstenone (Bottle \#1).

In order to ensure that we are not merely uncovering general odor detection with sociopolitical attitudes, we correlated respondents' self-reported perception of androstenone intensity with the control solvents. Detection of propylene glycol had a positive correlation with androstenone intensity $(\mathrm{r}=.17, \mathrm{p}<.05)$, though not with self-reported pleasantness of the solvent $(\mathrm{r}=.007, \mathrm{p}=.96)$. Likewise, citronella detection was positively correlated with androstenone intensity $(\mathrm{r}=.39, \mathrm{p}<.001)$, though citronella's perceived pleasantness was not $(\mathrm{r}=$ $.03, \mathrm{p}=.74)$. As a further check, we correlated detection and perceived pleasantness of propylene 
glycol and citronella with the sociopolitical batteries in question and found no significant correlations between the control solvents and constructs of interest.

Variations in people's political orientations are measured in several different ways. One is an exclusively political version of the Wilson-Patterson Index ${ }^{98}$, which asks participants how strongly they agree or disagree (on a five-point scale) with a set of 28 individual political items, including gay marriage, protecting gun rights, and increasing military spending (full listing in the Appendix). Responses to each item were coded such that higher scores correspond to a conservative position and then summed to obtain an overall measure of issue-based political conservatism. Using a schema developed by Smith et al. ${ }^{99}$ we measure broader social preferences using 15 items gauging the extent to which participants agreed or disagreed with statements like "government should not interfere with the fact that some people will be naturally more successful than others." Responses were coded such that higher scores for each of these items indicate more conservative preferences, with scores summed to obtain an additive "Society Works Best" (SWB) scale. For more information on Society Works Best, see Hibbing et al., ${ }^{100}$ as well as Friesen and Ksiazkiewicz. ${ }^{101}$

Finally, a distinct battery of five items asked respondents about their preferences for social order; for example, whether they prefer leaders to be firm and decisive, rule-breakers to be harshly punished, and public policies to stress protection. Responses were coded such that higher scores for each of these items indicate a stronger desire for clear social order and individual scores were summed to obtain an additive index. ${ }^{1}$ These three batteries are highly correlated ( $\mathrm{r}$ for SWB-WP $=.75 ; \mathrm{r}$ for SWB-Social Order $=.65 ; \mathrm{r}$ for WP-Social Order $=.66$ ) suggesting that, though they pick up unique features, they tap into a similar general construct. Age, gender,

\footnotetext{
${ }^{1}$ Items for preferences for social order and "Society Works Best" are listed in the appendix.
} 
income and education were also recorded in the surveys taken by the participants and are included as control variables.

\section{Results}

We first investigate androstenone detection and political orientations using the aforementioned personality, psychological, and political batteries. In addition to the three measures of political ideological, the survey also tapped cognitive and personality patterns, including the Big 5 personality inventory (conscientiousness, emotional stability, openness, agreeableness, and extroversion), the BIS/BAS (behavioral inhibition and activation, respectively) scales, preference for literalism, and tendencies to be both disgust and threat sensitive. We have no strong expectations for the nature of the relationship between androstenone detection and these concepts but we do expect positive relationships for all three of our political batteries and particularly for the "preferences for social order" battery, a finding that would indicate that those with politically conservative and "authority attuned" positions tend to be more sensitive to androstenone.

The results for all of these batteries are presented in Table 1. The first column of numbers reports Pearson correlations between self-reported odor intensity and the corresponding variable. With regard to the Big-5 personality battery, we find no relationship between androstenone intensity and conscientiousness $(r=-.09, \mathrm{p}>.10)$, emotional stability $(\mathrm{r}=.01, \mathrm{p}>.10)$, openness $(\mathrm{r}=.02, \mathrm{p}>.10)$, agreeableness $(\mathrm{r}=.11, \mathrm{p}>.10)$, or extroversion $(\mathrm{r}=.07, \mathrm{p}>.10)$. Moreover, there was no significant bivariate correlation between behavioral inhibition $(r=-.06, p>.10)$ or behavioral activation $(\mathrm{r}=.02, \mathrm{p}>.10)$. Preferences for literalism were positively correlated with androstenone intensity, albeit at a relaxed level of significance $(r=.16, p<.10)$, with higher preferences for literalism associated with higher self-reports of androstenone intensity. The same 
trended for disgust sensitivity and androstenone intensity $(\mathrm{r}=.16, \mathrm{p}<.10)$, with higher levels of disgust sensitivity being associated with more intense self-reports of androstenone detection.

Threat sensitivity was also positively correlated with androstenone intensity $(\mathrm{r}=.17, \mathrm{p}<.05)$.

Table 1: Androstenone Detection Correlated with Personality, Psychological, and Political Batteries

\begin{tabular}{|c|c|c|}
\hline Personality Batteries & Corr. & Partial Corr. \\
\hline Conscientiousness & -.09 & -.04 \\
\hline Emotional Stability & .01 & .05 \\
\hline Openness & .02 & .11 \\
\hline Agreeableness & .11 & .13 \\
\hline Extroversion & .07 & .12 \\
\hline \multicolumn{3}{|l|}{ Psychological Batteries } \\
\hline Behavioral Inhibition (BIS) & -.06 & -.11 \\
\hline Behavioral Activation (BAS) & .02 & .02 \\
\hline Literalism & $.16^{\#}$ & .13 \\
\hline Disgust & $.16^{\#}$ & -.02 \\
\hline Threat & $.17^{*}$ & .05 \\
\hline \multicolumn{3}{|l|}{ Political Batteries } \\
\hline Society Works Best & .10 & .13 \\
\hline Preferences for Social Order & $.19^{*}$ & $.21 *$ \\
\hline Wilson-Patterson Full Battery & .10 & .09 \\
\hline Sex/Reproduction Subset & .12 & .12 \\
\hline Economic Issues Subset & .04 & -.01 \\
\hline
\end{tabular}

Two-tailed significance tests, $\# \mathrm{p}<.10,{ }^{*} \mathrm{p}<.05$

Coefficients in the first column are simple correlations.

Coefficients in the second column are partial correlations controlling for age, gender, income, and education.

Turning to the political batteries, androstenone intensity was positively correlated with the Preferences for Social Order battery $(\mathrm{r}=.19, \mathrm{p}<.05)$, with subjects reporting higher preferences for social order also typically reporting higher androstenone intensity. Intensity, however, was not associated with the Society Works Best scale $(\mathrm{r}=.10, \mathrm{p}>.10)$ or full Wilson- 
Patterson battery $(\mathrm{r}=.10, \mathrm{p}>.10)$, nor was it associated with either the sex/reproduction $(\mathrm{r}=.12$, $\mathrm{p}>.10)$ or economic issues $(\mathrm{r}=.04, \mathrm{p}>.10)$ subsets of the Wilson-Patterson battery.

The second column reports partial correlations after accounting for the effects of age, gender, income, and education. The best indicator of the presence of an independent relationship is provided when standard control variables are partialed out (Column 2). We find no relationships between androstenone and either personality ( $\mathrm{p}>.10$ in all cases) or psychological $(p>.10)$ batteries. There was no significant partial correlation between the Society Works Best scale and androstenone intensity $(r=.13, p>.10)$, though we do find that androstenone intensity continues to exhibit a significant positive relationship with preferences for social order $(r=.21, p$ $<.05)$ even after accounting for the effect of our control variables. Neither the full WilsonPatterson battery $(\mathrm{r}=.09, \mathrm{p}>.10)$ nor the sex/reproduction subset $(\mathrm{r}=.12, \mathrm{p}>.10)$ and economic issues subset $(r=-.01, p>.10)$ were related to self-reported androstenone intensity.

With low effect sizes and non-significance, the strength of the connection between variations in androstenone detection and political views does not seem to be related specifically to economic or sexual morality items. The lack of relationship with sex attitudes is somewhat surprising, given androstenone's connection to gender signals in the extant literature, but this might indicate that androstenone affects inter-personal interactions, perceptions, and judgments but not necessarily preferences for sexual policies that would affect communities and society.

Though these results are somewhat promising, the simplicity of the models shown here particularly those models showing systematic relationships between androstenone intensity and political batteries - demand more scrutiny. We are particularly interested in subjecting the relationship between respondents' preferences for social order and androstenone detection, given that it is both of central interest in this research and the only sociopolitical battery to show a 
relationship with olfaction. Recall that in our correlational analyses, the scales were constructed through summation of their constituent parts, which, while parsimonious, risks confounding meaningful variance with error variance due to the fact that simple summation does not partition out the variability in individual items that are not related to the construct as a whole.

To further examine the relationship between preferences for social order in a more rigorous way, we constructed a structural equation model simultaneously specifying a factor model of the preferences for social order battery and then regressing the resulting latent factor for social order on androstenone intensity, sex, age, income, and education. The results of this analysis are shown in Table 2.

Table 2. Structural Equation Models Predicting Preferences for Social Order Measurement Coefficients

LV: Preferences for Social Order

Traditional Values 1.000

Decisive Leaders $1.033 * *(0.198)$

Protect Against External Threats

$0.914 * *(0.163)$

Strictly Punish Rulebreakers $0.923 * *(0.168)$

Benefit the Rich $0.503 * *(0.122)$

Maximum Govt. Involvement in Society $0.367 *(0.157)$

\section{Regression}

DV: Preferences for Social Order

$\begin{array}{rc}\text { Androstenone Intensity } & 0.121^{*}(0.059) \\ \text { Sex } & 0.146(0.281) \\ \text { Age } & 0.004(0.011) \\ \text { Income } & 0.234 *(0.089) \\ \text { Education } & -0.134(0.083) \\ \chi^{2} & 44.78 \\ \text { df } & 34 \\ \mathrm{~N} & 135 \\ \text { CFI } & 0.932 \\ \text { RMSEA } & 0.048\end{array}$

Two-tailed significance tests, ${ }^{*} \mathrm{p}<.05,{ }^{* *} \mathrm{p}<.01$ 


\section{Standard errors in parentheses}

The structural equation model was estimated using the Lavaan package in $R$.

The factor model for individuals' preferences for social order, when regressed on androstenone intensity and our control variables, continued to show a positive and significant relationship with androstenone intensity $(b=.121, \mathrm{p}<.05)$. As in the partial correlation for this survey battery, participants who reported higher intensities of androstenone detection were also typically more prone to having heightened preferences for social order. That this relationship persists when our data is subjected to increasingly rigorous methodological tests suggests that it is a connection between biology and preferences necessitating further investigation. Importantly,

note that though there are known gender differences in androstenone detection and production, ${ }^{102}$ there is no relationship between sex and preferences for social order - so it might be possible that reported biological sex is not a moderator between androstenone intensity and preferences for social order. ${ }^{103}$ These results, combined with the relationship between androstenone detection and our battery tapping preferences for organizing society, is consistent with our earlier theoretical speculation that androstenone detection would be most apparent on issues pertaining to securing the social order.

\section{Discussion}

In our sample, variations in androstenone detection appear to be relevant to variations in political - specifically preferences for order - but not psychological orientations. Economic and sexual morality issues appear to be unconnected to sensitivity to androstenone. As we noted earlier, the absence of a relationship with sex items is particularly interesting given that other research demonstrates sensitivity to pathogen-relevant disgust is indeed related to issue stances on sexual matters. Sensitivity to the human odorant androstenone appears to manifest itself 
politically in quite a different fashion than sensitivity to pathogen-indicating odors (e.g., human excrement, vomit, spoiled food). Certain individuals are sensitive to the odor of androstenone, and they also tend to be the people who are attuned to and eager to squelch threats to the social order. We also recognize the limitations of our study. The sample is quite small, given the effect sizes of these relationships, and though we use an adult (rather than student) population, it is geographically constrained and racially homogenous. Because of these limitations, we have tried to be careful in drawing any broad conclusions or extending our findings to other populations other than the one from which we sampled. We hope that this effort at connecting these domains provides a foundation for future research, particularly for a priori power analysis, research design, and replication and extension.

Variation in androstenone detection has been related to small-scale social and emotional responses, such as reactions to facial images. In this study, we examined whether variation in androstenone detection is also related to mass-scale political orientations. Given the nature of androstenone as it relates to hormones like testosterone, we reasoned that, if there is a relationship with politics, it is likely to center on issues concerning dominance, authority, hierarchy, competition, leadership, and security; in short, social order. Preliminary tests support the connection of androstenone detection to general political orientations, with further indication that preferences for social order are more affected than preferences for policies related to the economy, sex, and reproduction. This relationship of androstenone to social order and hierarchy supports the hormone's connection to testosterone - that is, those sensitive to testosterone-related behaviors like aggression may desire strong leadership and tight ingroup coalitions to mitigate what they see as social disruption. 
Setting aside the need to replicate this research at a larger scale, the evidence we present of a connection between olfactory sensitivity and political orientations is novel, intriguing and supports previous work on individual responses to various pheromones. The suggestive relationship between political orientations and olfactory sensitivity to the odor of androstenone should encourage additional work in olfaction and politics - not just that portion of olfaction related to disgusting odors. Though people are not consciously aware of their sensitivities to odors such as androstenone, it would appear that subthreshold detection is enough to exert a modest effect on some political orientations. Much like work conducted on non-conscious physiological responses to stimuli and associated political attitudes ${ }^{104} 105$ 106, subthreshold detection of environmental signals may help us bypass many of the problems with survey selfreporting and lead to a fuller understanding of individual variation in preferences for group life. It would be particularly useful to test larger samples that could be split or moderated by sex to detect differences in how male and female responses to the hormone may alter its relationship with social preferences. Measuring gender in addition to binary sex also might reveal nuance differences in gender orientation, gender identity strength, and attitudes toward strong leaders, social order and hierarchy. ${ }^{107}$

Psychologists, biologists and geneticists have demonstrated human variation in every sensory system just as social scientists have been examining differences in social and political orientations and attitudes. Our work seeks to bridge these worlds in the hope of contributing to the understanding of the nature and origins of human political behavior and, broadly, public opinion. Few if any disciplines treat biological and behavioral variation as completely unrelated, yet much of the existing political science research does just that. This is a matter of empiricism. Just as parents, schools, peers, culture and time periods may influence socio-political attitudes 
and behavior, we posit that the manner in which individuals process these environmental inputs may be just as important as the inputs themselves ${ }^{108}$. Combined with the growing body of work connecting politics to behavioral genetics and physiology, we demonstrate olfaction should not be ignored in the examination of political attitudes and orientations.

\footnotetext{
${ }^{1}$ Yoel Inbar, David A. Pizarro, and Paul Bloom, "Conservatives Are More Easily Disgusted than Liberals," Cognition \& Emotion 23, no. 4 (2009): 714, https://doi.org/10.1080/02699930802110007.

2 Amanda Balzer and Carly M. Jacobs, "Gender and Physiological Effects in Connecting Disgust to Political Preferences," Social Science Quarterly 92, no. 5 (December 1, 2011): 1297-1313, https://doi.org/10.1111/j.15406237.2011.00819.x.

${ }^{3}$ Kevin B. Smith et al., "Disgust Sensitivity and the Neurophysiology of Left-Right Political Orientations," PLoS ONE 6, no. 10 (October 19, 2011): e25552, https://doi.org/10.1371/journal.pone.0025552.

${ }^{4}$ Jacob M. Vigil, "Political Leanings Vary with Facial Expression Processing and Psychosocial Functioning," Group Processes \& Intergroup Relations 13, no. 5 (September 1, 2010): 547-58, https://doi.org/10.1177/1368430209356930.

${ }^{5}$ Douglas R. Oxley et al., "Political Attitudes Vary with Physiological Traits," Science 321 (2008): 1667-70.

${ }^{6}$ Pierre Gloor and Alan H. Guberman, "The Temporal Lobe \& Limbic System," Canadian Medical Association Journal 157, no. 11 (December 1, 1997): 1597-98.

${ }^{7}$ See, for example, James Woodward and John Allman, "Moral Intuition: Its Neural Substrates and Normative Significance," Journal of Physiology-Paris, The Evolution of Human Cognition and Neuroscience: a Dialogue between Scientists and Humanists, 101, no. 4 (July 1, 2007): 179-202, https://doi.org/10.1016/j.jphysparis.2007.12.003.

${ }^{8}$ Wen Zhou and Denise Chen, "Sociochemosensory and Emotional Functions: Behavioral Evidence for Shared Mechanisms," Psychological Science 20, no. 9 (September 1, 2009): 1118-24, https://doi.org/10.1111/j.14679280.2009.02413.x.

${ }^{9}$ Kevin R. Neville and Lewis B. Haberly, "Olfactory Cortex," in The Synaptic Organization of the Brain, ed. Gordon M. Shepherd, 5th ed. (Oxford: Oxford University Press, 2003), 415-54.

${ }^{10}$ Umberto Castiello et al., "Cross-Modal Interactions between Olfaction and Vision When Grasping," Chemical Senses 31, no. 7 (September 1, 2006): 665-71, https://doi.org/10.1093/chemse/bj1007.

${ }^{11}$ Ann Marie Fiore, Xinlu Yah, and Eunah Yoh, "Effects of a Product Display and Environmental Fragrancing on Approach Responses and Pleasurable Experiences," Psychology \& Marketing 17, no. 1 (January 1, 2000): 27-54, https://doi.org/10.1002/(SICI)1520-6793(200001)17:1<27::AID-MAR3>3.0.CO;2-C.

${ }^{12}$ Maureen Morrin and S Ratneshwar, "The Impact of Ambient Scent on Evaluation, Attention, and Memory for Familiar and Unfamiliar Brands," Journal of Business Research 49, no. 2 (August 1, 2000): 157-65, https://doi.org/10.1016/S0148-2963(99)00006-5.

${ }^{13}$ Johan N. Lundström and Mats J. Olsson, "Subthreshold Amounts of Social Odorant Affect Mood, but Not Behavior, in Heterosexual Women When Tested by a Male, but Not a Female, Experimenter," Biological Psychology 70, no. 3 (December 1, 2005): 197-204, https://doi.org/10.1016/j.biopsycho.2005.01.008.

${ }^{14}$ Thomas R. Insel and Larry J. Young, "The Neurobiology of Attachment," Nature Reviews Neuroscience 2, no. 2 (February 2001): 129-36, https://doi.org/10.1038/35053579.

${ }^{15}$ Andreas Keller, "Genes and Smells," The Biochemical Society, no. December (2011): 10-13.

${ }^{16}$ Jacob Vigil, "Facial Expression Processing Varies with Political Affiliation," October 19, 2008, http://precedings.nature.com/documents/2414/version/1.

${ }^{17}$ Vigil.

${ }^{18}$ Oxley et al., "Political Attitudes Vary with Physiological Traits."
} 
${ }^{19}$ Lauralee Sherwood, Human Physiology: From Cells to Systems, 7th ed. (Australia ; United States: Brooks/Cole, Cengage Learning, 2010).

${ }^{20}$ Lene Aarøe, Michael Bang Petersen, and Kevin Arceneaux, "The Behavioral Immune System Shapes Political Intuitions: Why and How Individual Differences in Disgust Sensitivity Underlie Opposition to Immigration,”

American Political Science Review 111, no. 2 (May 2017): 277-94, https://doi.org/10.1017/S0003055416000770.

${ }^{21}$ Inbar, Pizarro, and Bloom, "Conservatives Are More Easily Disgusted than Liberals."

${ }^{22}$ Balzer and Jacobs, "Gender and Physiological Effects in Connecting Disgust to Political Preferences."

${ }^{23}$ Smith et al., "Disgust Sensitivity and the Neurophysiology of Left-Right Political Orientations."

${ }^{24}$ Joshua M. Tybur, Debra Lieberman, and Vladas Griskevicius, "Microbes, Mating, and Morality: Individual Differences in Three Functional Domains of Disgust," Journal of Personality and Social Psychology 97, no. 1 (July 2009): 103-22, https://doi.org/10.1037/a0015474.

${ }^{25}$ Joshua M. Tybur et al., "Extending the Behavioral Immune System to Political Psychology: Are Political Conservatism and Disgust Sensitivity Really Related?," Evolutionary Psychology 8, no. 4 (October 1, 2010): 147470491000800420, https://doi.org/10.1177/147470491000800406.

${ }^{26}$ Steven L. Neuberg, Douglas T. Kenrick, and Mark Schaller, "Human Threat Management Systems: SelfProtection and Disease Avoidance," Neuroscience \& Biobehavioral Reviews, Threat-Detection and Precaution: Neuro-physiological, Behavioral, Cognitive and Psychiatric Aspects, 35, no. 4 (March 1, 2011): 1042-51, https://doi.org/10.1016/j.neubiorev.2010.08.011.

${ }^{27}$ Suma Jacob et al., "Psychological Effects of Musky Compounds: Comparison of Androstadienone with Androstenol and Muscone," Hormones and Behavior 42, no. 3 (November 1, 2002): 274-83, https://doi.org/10.1006/hbeh.2002.1826.

${ }^{28}$ Bettina M. Pause, "Are Androgen Steroids Acting as Pheromones in Humans?," Physiology \& Behavior, Special Section on Olfactory Perception, Communication, and the Nose-to-Brain Pathway, 83, no. 1 (October 30, 2004): $21-$ 29, https://doi.org/10.1016/j.physbeh.2004.07.019.

${ }^{29}$ Lundström and Olsson, "Subthreshold Amounts of Social Odorant Affect Mood, but Not Behavior, in Heterosexual Women When Tested by a Male, but Not a Female, Experimenter."

${ }^{30}$ Tamsin K. Saxton et al., "Evidence That Androstadienone, a Putative Human Chemosignal, Modulates Women's Attributions of Men's Attractiveness," Hormones and Behavior 54, no. 5 (November 1, 2008): 597-601, https://doi.org/10.1016/j.yhbeh.2008.06.001.

${ }^{31}$ Rose McDermott, Dustin Tingley, and Peter K. Hatemi, "Assortative Mating on Ideology Could Operate Through Olfactory Cues," American Journal of Political Science 58, no. 4 (October 1, 2014): 997-1005, https://doi.org/10.1111/ajps.12133.

32 John P. Kline, Gary E. Schwartz, and Ziya V. Dikman, "Interpersonal Defensiveness and Diminished Perceptual Acuity for the Odor of a Putative Pheromone: Androstenone," Biological Psychology 74, no. 3 (March 1, 2007): 405-13, https://doi.org/10.1016/j.biopsycho.2006.10.003.

${ }^{33}$ Tom A. Hummer and Martha K. McClintock, "Putative Human Pheromone Androstadienone Attunes the Mind Specifically to Emotional Information," Hormones and Behavior 55, no. 4 (April 1, 2009): 548-59, https://doi.org/10.1016/j.yhbeh.2009.01.002.

${ }^{34}$ Zhou and Chen, "Sociochemosensory and Emotional Functions."

${ }^{35}$ Vicky A. Tobin et al., "An Intrinsic Vasopressin System in the Olfactory Bulb Is Involved in Social Recognition," Nature 464, no. 7287 (March 2010): 413-17, https://doi.org/10.1038/nature08826.

${ }^{36}$ Ursula Stockhorst and Reinhard Pietrowsky, "Olfactory Perception, Communication, and the Nose-to-Brain Pathway," Physiology \& Behavior, Special Section on Olfactory Perception, Communication, and the Nose-to-Brain Pathway, 83, no. 1 (October 30, 2004): 3-11, https://doi.org/10.1016/j.physbeh.2004.07.018.

${ }^{37}$ Peter Mombaerts, "Molecular Biology of Odorant Receptors in Vertebrates," Annual Review of Neuroscience 22, no. 1 (1999): 487-509, https://doi.org/10.1146/annurev.neuro.22.1.487.

${ }^{38}$ Sherwood, Human Physiology.

${ }^{39}$ Insel and Young, "The Neurobiology of Attachment."

${ }^{40}$ Tobin et al., "An Intrinsic Vasopressin System in the Olfactory Bulb Is Involved in Social Recognition."

${ }^{41}$ Michael Kosfeld et al., "Oxytocin Increases Trust in Humans," Nature 435, no. 7042 (June 2005): 673-76, https://doi.org/10.1038/nature03701.

42 Tobin et al., "An Intrinsic Vasopressin System in the Olfactory Bulb Is Involved in Social Recognition."

${ }^{43}$ Antonio R. Damasio and Hanna Damasio, "Cortical Systems for Retrieval of Concrete Knowledge: The Convergence Zone Framework," in Large-Scale Neuronal Theories of the Brain, ed. Christof Koch and Joel L. Davis (Boston: MIT Press, 1994), 61-74. 
${ }^{44}$ Though see McDermott, Tingley, and Hatemi, “Assortative Mating on Ideology Could Operate Through Olfactory Cues."

${ }^{45}$ Peter Hatemi and Rose McDermott, "Policing the Perimeter: Disgust and Purity in Democratic Debate," PS:

Political Science \& Politics 45, no. 4 (October 2012): 675-87, https://doi.org/10.1017/S1049096512000686.

${ }^{46}$ Milton Lodge and Charles S. Taber, "The Automaticity of Affect for Political Leaders, Groups, and Issues: An

Experimental Test of the Hot Cognition Hypothesis," Political Psychology 26, no. 3 (June 2005): 455-82,

https://doi.org/10.2307/3792606.

${ }^{47}$ Oxley et al., "Political Attitudes Vary with Physiological Traits."

${ }^{48}$ Jonathan Haidt and Jesse Graham, "When Morality Opposes Justice: Conservatives Have Moral Intuitions That

Liberals May Not Recognize,” Social Justice Research 20, no. 1 (March 1, 2007): 98-116,

https://doi.org/10.1007/s11211-007-0034-z.

${ }^{49}$ Inbar, Pizarro, and Bloom, "Conservatives Are More Easily Disgusted than Liberals."

${ }^{50}$ E.g., Hatemi and McDermott, "Policing the Perimeter."

${ }^{51}$ Smith et al., "Disgust Sensitivity and the Neurophysiology of Left-Right Political Orientations."

${ }^{52}$ Balzer and Jacobs, "Gender and Physiological Effects in Connecting Disgust to Political Preferences."

${ }^{53}$ Theodor W. Adorno and Else Frenkel-Brunswik, The Authoritarian Personality, Abr Rei (W W Norton \& Co Inc, 1950).

${ }^{54}$ Jesse Graham, Jonathan Haidt, and Brian A Nosek, "Liberals and Conservatives Rely on Different Sets of Moral Foundations," Journal of Personality and Social Psychology 96, no. 5 (May 2009): 1029-46,

https://doi.org/10.1037/a0015141.

${ }_{55}$ McDermott, Tingley, and Hatemi, “Assortative Mating on Ideology Could Operate Through Olfactory Cues."

${ }^{56}$ Hummer and McClintock, "Putative Human Pheromone Androstadienone Attunes the Mind Specifically to Emotional Information."

${ }^{57}$ Jan Havlicek et al., "Current Issues in the Study of Androstenes in Human Chemosignaling," in Vitamins \& Hormones, ed. Gerald Litwack, vol. 83, Pheromones (Academic Press, 2010), 47-81, https://doi.org/10.1016/S00836729(10)83003-1.

${ }^{58}$ Johan N. Lundström et al., "A Putative Social Chemosignal Elicits Faster Cortical Responses than Perceptually Similar Odorants," NeuroImage 30, no. 4 (May 1, 2006): 1340-46,

https://doi.org/10.1016/j.neuroimage.2005.10.040.

${ }^{59}$ Havlicek et al., "Current Issues in the Study of Androstenes in Human Chemosignaling."

${ }^{60}$ Elizabeth A. Bremner et al., "The Prevalence of Androstenone Anosmia," Chemical Senses 28, no. 5 (June 1, 2003): 423-32, https://doi.org/10.1093/chemse/28.5.423.

${ }^{61}$ Keller, "Genes and Smells."

${ }^{62}$ Idan Menashe et al., "Different Noses for Different People," Nature Genetics 34, no. 2 (June 2003): 143, https://doi.org/10.1038/ng1160.

${ }^{63}$ Bettina M. Pause, Roman Ferstl, and Gabriele Fehm-Wolfsdorf, "Personality and Olfactory Sensitivity," Journal of Research in Personality 32, no. 4 (December 1, 1998): 510-18, https://doi.org/10.1006/jrpe.1998.2228.

${ }^{64}$ Havlicek et al., "Current Issues in the Study of Androstenes in Human Chemosignaling."

${ }^{65}$ Tim J. C. Jacob et al., "Changes in the Odor Quality of Androstadienone During Exposure-Induced Sensitization," Chemical Senses 31, no. 1 (January 1, 2006): 3-8, https://doi.org/10.1093/chemse/bji073.

${ }^{66}$ Antti Knaapila et al., "Genetic and Environmental Contributions to Perceived Intensity and Pleasantness of Androstenone Odor: An International Twin Study," Chemosensory Perception 1, no. 1 (March 1, 2008): 34-42, https://doi.org/10.1007/s12078-007-9005-x.

${ }^{67}$ Havlicek et al., "Current Issues in the Study of Androstenes in Human Chemosignaling."

${ }^{68}$ C. J. Wysocki and G. K. Beauchamp, "Ability to Smell Androstenone Is Genetically Determined," Proceedings of the National Academy of Sciences 81, no. 15 (August 1, 1984): 4899-4902, https://doi.org/10.1073/pnas.81.15.4899.

${ }^{69}$ Knaapila et al., "Genetic and Environmental Contributions to Perceived Intensity and Pleasantness of Androstenone Odor."

${ }^{70}$ Andreas Keller et al., "Genetic Variation in a Human Odorant Receptor Alters Odour Perception," Nature 449, no. 7161 (September 2007): 468-72, https://doi.org/10.1038/nature06162.

${ }^{71}$ Keller, "Genes and Smells."

${ }^{72}$ Liwei Wang, Lixin Chen, and Tim Jacob, "Evidence for Peripheral Plasticity in Human Odour Response," The Journal of Physiology 554, no. 1 (January 1, 2004): 236-44, https://doi.org/10.1113/jphysiol.2003.054726.

${ }^{73}$ Rachel S. Herz, "Verbal Priming and Taste Sensitivity Make Moral Transgressions Gross," Behavioral Neuroscience 128, no. 1 (2014): 20-28, https://doi.org/10.1037/a0035468. 
${ }^{74}$ Keller, "Genes and Smells," 13.

${ }^{75}$ Kline, Schwartz, and Dikman, "Interpersonal Defensiveness and Diminished Perceptual Acuity for the Odor of a Putative Pheromone."

${ }^{76}$ J. J. Cowley, A. L. Johnson, and B. W. L. Brooksbank, "The Effect of Two Odorous Compounds on Performance in an Assessment-of-People Test," Psychoneuroendocrinology 2, no. 2 (January 1, 1977): 159-72, https://doi.org/10.1016/0306-4530(77)90021-X.

${ }^{77}$ M.D. Kirk-Smith, David A. Booth, and H. Van Der Starre, "Effects of Androstenone on Choice of Location in Others' Presence," in Olfaction and Taste VII: Proceedings of the Seventh International Symposium on Olfaction and Taste and of the Fourth Congress of the European Chemoreception Research Organization (Devon, UK: IRL Press, 1980), https://www.researchgate.net/publication/236963818_Effect_of_androstenone_on_choice_of_location_in_others'pp resence.

${ }^{78}$ see also Andrew R. Gustavson, Michael E. Dawson, and Douglas G. Bonett, "Androstenol, a Putative Human Pheromone, Affects Human (Homo Sapiens) Male Choice Performance," Journal of Comparative Psychology 101, no. 2 (1987): 210-12, https://doi.org/10.1037/0735-7036.101.2.210.

${ }^{79}$ Erik E. Filsinger et al., "Human (Homo Sapiens) Responses to the Pig (Sus Scrofa) Sex Pheromone 5 AlphaAndrost-16-En-3-One," Journal of Comparative Psychology 98, no. 2 (1984): 219-22, https://doi.org/10.1037/07357036.98.2.219.

${ }^{80}$ Kline, Schwartz, and Dikman, "Interpersonal Defensiveness and Diminished Perceptual Acuity for the Odor of a Putative Pheromone."

${ }^{81}$ Hummer and McClintock, "Putative Human Pheromone Androstadienone Attunes the Mind Specifically to Emotional Information."

${ }^{82}$ For reviews of the broader correlates of androstenone detection, see Schaal and Porter 1991; Havlicek et al. 2010; Kline et al. 2006

${ }^{83}$ Vigil, "Political Leanings Vary with Facial Expression Processing and Psychosocial Functioning."

${ }^{84}$ Oxley et al., "Political Attitudes Vary with Physiological Traits."

${ }^{85}$ D. B. Gower and B. A. Ruparelia, "Olfaction in Humans with Special Reference to Odorous 16-Androstenes: Their Occurrence, Perception and Possible Social, Psychological and Sexual Impact," Journal of Endocrinology 137, no. 2 (May 1, 1993): 167-87, https://doi.org/10.1677/joe.0.1370167.

${ }^{86}$ Alan Booth et al., "Testosterone and Social Behavior," Social Forces 85, no. 1 (September 1, 2006): 167-91, https://doi.org/10.1353/sof.2006.0116.

${ }^{87}$ Rose McDermott et al., "Testosterone and Aggression in a Simulated Crisis Game," The Annals of the American Academy of Political and Social Science 614 (2007): 15-33.

${ }^{88}$ Robert Altemeyer, The Authoritarian Specter (Cambridge, Mass: Harvard University Press, 1996).

${ }^{89}$ Stanley Feldman and Karen Stenner, "Perceived Threat and Authoritarianism," Political Psychology 18, no. 4 (December 1, 1997): 741-70, https://doi.org/10.1111/0162-895X.00077.

${ }^{90}$ Karen Stenner, The Authoritarian Dynamic (New York: Cambridge University Press, 2005).

${ }^{91}$ Marc J. Hetherington and Jonathan D. Weiler, Authoritarianism and Polarization in American Politics, 1 edition (New York: Cambridge University Press, 2009).

${ }^{92}$ Keller et al., "Genetic Variation in a Human Odorant Receptor Alters Odour Perception."

${ }^{93}$ Keller et al.

${ }^{94}$ Keller et al.

${ }^{95}$ Knaapila et al., "Genetic and Environmental Contributions to Perceived Intensity and Pleasantness of Androstenone Odor."

${ }^{96}$ a practice advised by Keller et al., "Genetic Variation in a Human Odorant Receptor Alters Odour Perception."

${ }^{97}$ Knaapila et al., "Genetic and Environmental Contributions to Perceived Intensity and Pleasantness of Androstenone Odor."

${ }^{98}$ Glenn D. Wilson and John R. Patterson, "A New Measure of Conservatism," British Journal of Social and Clinical Psychology 7, no. 4 (December 1, 1968): 264-69, https://doi.org/10.1111/j.2044-8260.1968.tb00568.x.

${ }^{99}$ Kevin B. Smith et al., "Linking Genetics and Political Attitudes: Reconceptualizing Political Ideology," Political Psychology 32, no. 3 (2011): 369-397, https://doi.org/10.1111/j.1467-9221.2010.00821.x.

100 Predisposed: Liberals, Conservatives, and the Biology of Political Differences (New York: Routledge, 2013).

${ }^{101}$ Amanda Friesen and Aleksander Ksiazkiewicz, "Do Political Attitudes and Religiosity Share a Genetic Path?," Political Behavior 37, no. 4 (December 1, 2015): 791-818, https://doi.org/10.1007/s11109-014-9291-3. 
102 e.g., Cowley, Johnson, and Brooksbank, "The Effect of Two Odorous Compounds on Performance in an Assessment-of-People Test."

${ }^{103} \mathrm{We}$ also ran a structural model specifying an preferences for social order regressed on a sex*androstenone intensity interaction; this interaction was not found to be significantly related to preferences for social order.

${ }^{104}$ Amanda Friesen, Kevin B. Smith, and John R. Hibbing, "Physiological Arousal and Self-Reported Valence for Erotica Images Correlate with Sexual Policy Preferences," International Journal of Public Opinion Research 29, no. 3 (September 1, 2017): 449-70, https://doi.org/10.1093/ijpor/edw008.

${ }^{105}$ Frank J. Gonzalez, Kevin B. Smith, and John R. Hibbing, "No Longer 'Beyond Our Scope': The Biological and Non-Conscious Underpinnings of Public Opinion," in New Directions in Public Opinion, ed. Adam J. Berinsky, 2nd ed. (New York: Routledge, 2016), 186-204.

${ }^{106}$ Michael W. Wagner et al., "Beyond Survey Self-Reports: Using Physiology to Tap Political Orientations," International Journal of Public Opinion Research 27, no. 3 (September 1, 2015): 303-17, https://doi.org/10.1093/ijpor/edu036.

${ }^{107}$ Amanda Bittner and Elizabeth Goodyear-Grant, "Sex Isn't Gender: Reforming Concepts and Measurements in the Study of Public Opinion," Political Behavior 39, no. 4 (December 1, 2017): 1019-41, https://doi.org/10.1007/s11109-017-9391-y.

${ }^{108}$ Gonzalez, Smith, and Hibbing, "No Longer 'Beyond Our Scope': The Biological and Non-Conscious Underpinnings of Public Opinion." 